17. Кошман В.С. Мир Фридмана, планковские величины и энергетическая модель эволюции Вселенной // Sciences of Europe. 2020. № 56. Vol. 1. pp. $17-20$.

18. Кошман В.С. Обоснование необходимости переосмысления феномена «эпоха Планка» / The scientific heritage. 2021. №64. Vol. 1. pp. 11 - 14.

19. Вайнберг С. Первые три минуты: Современный взгляд на происхождение Вселенной / пер. с англ. М.: Энергоиздат. 1981. - $208 \mathrm{c}$.

20. Зельманов А.А. Космология // Развитие астрономии в СССР. М.: Наука. 1967. С. 320 - 390.

21. Зельдович Я.Б. «Горячая» модель Вселенной // Избранные труды. Частицы, ядра, Вселенная. М.: Наука. С. $237-244 \mathrm{c}$.

22. Авакянц Л.П., Колесников С.В., Салецкий А.М. Введение в квантовую физику. Методика решения задач: учебное пособие. М.: Физический факультет МГУ. 2018. - 400 с.

23. Чернин А.Д. Как Гамов вычислил температуру реликтового излучения, или немного об искусстве теоретической физики // УФН. 1994. Т. 164. №8. С. 889 - 896.

\title{
Онуфриенок В.В. \\ Распределение вакансий в матрице пирита на различных глубинах залеганий породы
}

Красноярский государственный аграрный университет

doi: 10.18411/trnio-11-2021-77

(Россия, Красноярск)

\section{Аннотация}

Для изучения влияния давления на распределение вакансий в кристаллической структуре проанализирован пирит на разных глубинах залегания (до 567 м в пределах одной скважины). Химический состав минерала определен методом ЕРМА на растровом электронном микроскопе VEGA II LMU. Предложен метод расчета катионных и анионных вакансий в структуре пирита различного химического состава. Обнаружено, что катионные и анионные вакансии очень чувствительны к глубине залегания и, следовательно, к приложенному внешнему давлению. Показано, что с увеличением глубины линейная зависимость кривой «плотность вакансий - химический состав» смещается, а затем деформируется. На основе представленных исследований можно рекомендовать применение пирита в качестве гео - барометра.

Ключевые слова: атомы примеси, вакансия ионов, давление породы, глубина скважины, плотность вакансий.

\section{Abstract}

In order to study the effect of pressure on the crystal structure of minerals, the structure of pyrite was analyzed at different depths of its occurrence (up to $567 \mathrm{~m}$ ) within one well. The chemical composition of the mineral was determined by the EPMA method on a VEGA II LMU scanning electron microscope. A method is proposed for calculating cationic and anionic vacancies in the structure of pyrite of various chemical compositions. It was found that cationic and anionic vacancies are highly sensitive to the depth of the mineral, and hence to the applied external pressure. It is shown that with increasing depth, the linear dependence of the "vacancy density chemical composition" curve shifts and then deforms.

Keywords: the depths of occurrence, graphically, anionic and cationic vacancies.

\section{Введение}

Вакансии играют определяющую роль при переходе под воздействием внешнего давления пирротина из моноклинного в гексагональное кристаллической строение [1 - 4]. До настоящего времени остается во многом не изучено влияние давления на кристаллическую структуру пирита $[5,6]$.

Пирит содержит изоморфные примеси кобальта и никеля, а также меди, золота и, как правило, катионные и анионные вакансии [7-9]. Относительно высокая концентрация вакансий в структуре, несомненно, влияет на свойства пирита. Актуальность влияния давления на пирит обусловлена, в частности, и тем, что пирит - минерал, сопутствующий 
золоту в породе [10]. На примере одного минерала проведены исследования точечных дефектов на разных глубинах залегания породы.. Он содержит изоморфные примеси кобальта и никеля, а также меди, золота и, как правило, катионные и анионные вакансии $[11,12]$.

Формула пирита должна быть представлена как $\mathrm{AX}_{2}$, где $\mathrm{A}$ - такой химический элемент, как $\mathrm{Au}, \mathrm{Co}, \mathrm{Cu}, \mathrm{Fe}, \mathrm{Mn}, \mathrm{Ni}, \mathrm{Os}, \mathrm{Pd}, \mathrm{Pt}$ или Ru. X формулы может быть As, Bi, S, Sb, $\mathrm{Se}$ или Te [13]. Изоструктурная группа пирита в целом представлена пространственной группой Ра3 [14].

Цель исследования: на примере пирита провести анализ концентрации точечных дефектов различной природы. Предположить алгоритм расчета вакансий и атомов примеси. Рассчитать плотность вакансий для кубической структуры пирита на разных глубинах залегания породы. Получить критерий, устанавливающий распределение вакансии в пирите в зависимости от глубины залегания.

\section{Методы и подходы}

Пирит для исследований брался из золоторудного месторождения «Панимба», расположенного примерно в 200 км к северо-северо-востоку от Красноярска и примерно в 100 км к юго-востоку от городов Тея и Северо-Енисейский (Восточная Сибирь).

Зерна пирита извлекались из рудных руд путем измельчения их в металлической ступке до фракции $+0,5$ мм и дальнейшего обогащения водно-гравитационным методом. Мономинеральность гравитационного концентрата контролировалась с помощью бинокулярной лупы и после визуальной очистки составляла не менее $97 \%$.

Химический состав минерала определяли методом ЕРМА на растровом электронном микроскопе VEGA II LMU c интегрированной системой рентгеновского энергодисперсионного микроанализатора OXFORD INCA ENERGY 350.

Для подготовки образца к съемке исходный мелкокристаллический серый пирит истирали в ступке из нержавеющей стали до мелкого порошка и наносили одним слоем на «неотражающую» ячейку (монокристалл кремния, срезанный по плоскостям [910]), слегка смазанный вазелином.

\section{Результаты и обсуждения}

Результаты исследований пирита микрозондовым анализом представлены в виде графиков ни рис.2.и 3 . Построены графики, которые представлены на рис. 2 и рис. 3 . Из рисунков видно, что вакансии в структуре пирита с более глубоким уровнем залегания имеют более узкий интервал существования вдоль ось абсцисс (давление как бы сжимает кривые). Следует также отметить, что кривые катионных вакансий имеют другую зависимость - семь кривых анионных вакансий.

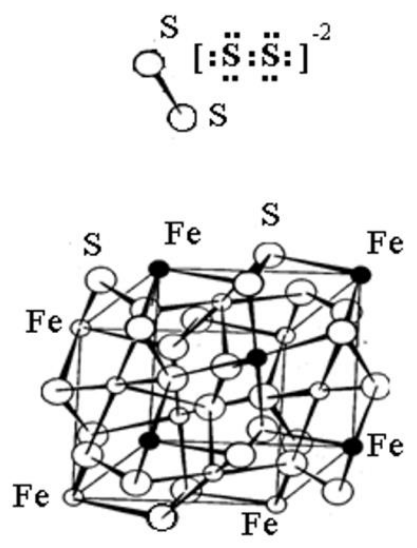

A

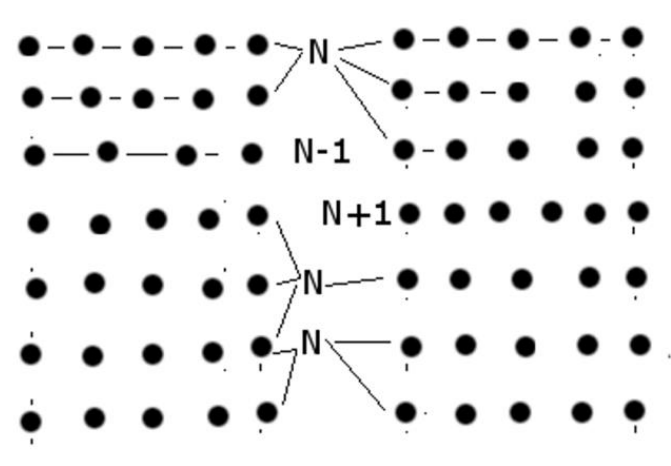

B
C

Рисунок 1. Кристаллическая структура идеального пирита и кристаллические матрицых в проекции [001] этой структуры с дефицитом и избытком ионов железа 
На рисунке 1 показано наглядное пояснение концепций отрицательных и положительных ионных вакансий. Итак, (N-1) - вакансия положительная, а значит, $(\mathrm{N}+1)$ отрицательная. Этот рисунок ясно объясняет концепцию положительной (N-1) и отрицательной $(\mathrm{N}+1)$ вакансии в кристаллической матрице. Когда в звене нет вакансии, то количество узлов $\mathrm{N}$.

На рис.2 показаны кривые катионных вакансий (сплошные точки на рисунках) и анионных вакансий (точки с неокрашенным центром) как пирита поверхностного слоя (50100 м, обозначение 1), так и более глубоких слоев (270-290 м, кривая 2).

Конечно, все образцы пирита содержали ионы примеси (например, в таблице 3 указаны ионы примеси кобальта и никеля в пирите), но их концентрация была на два порядка ниже, чем концентрация катионных (анионных) вакансий; поэтому их влияние на исследуемый эффект незначительно и им можно пренебречь.

Результаты лабораторных исследований пирита, обнаруженного в поверхностных слоях (до глубины 100 м), в таблицах не представлены, а показаны только на рисунке 2 (кривая 1). Это сделано для уменьшения дублирования данных. Отметим, что расчет катионных вакансий и анионных вакансий производился с учетом всех знаков после запятой, поэтому $\chi$ и $\tau$ значения, представленные в таблицах, округлены и отличаются от представленных в таблицах значений $(1-\chi)$ и $(1-\tau)$, поскольку последние даны без округления.

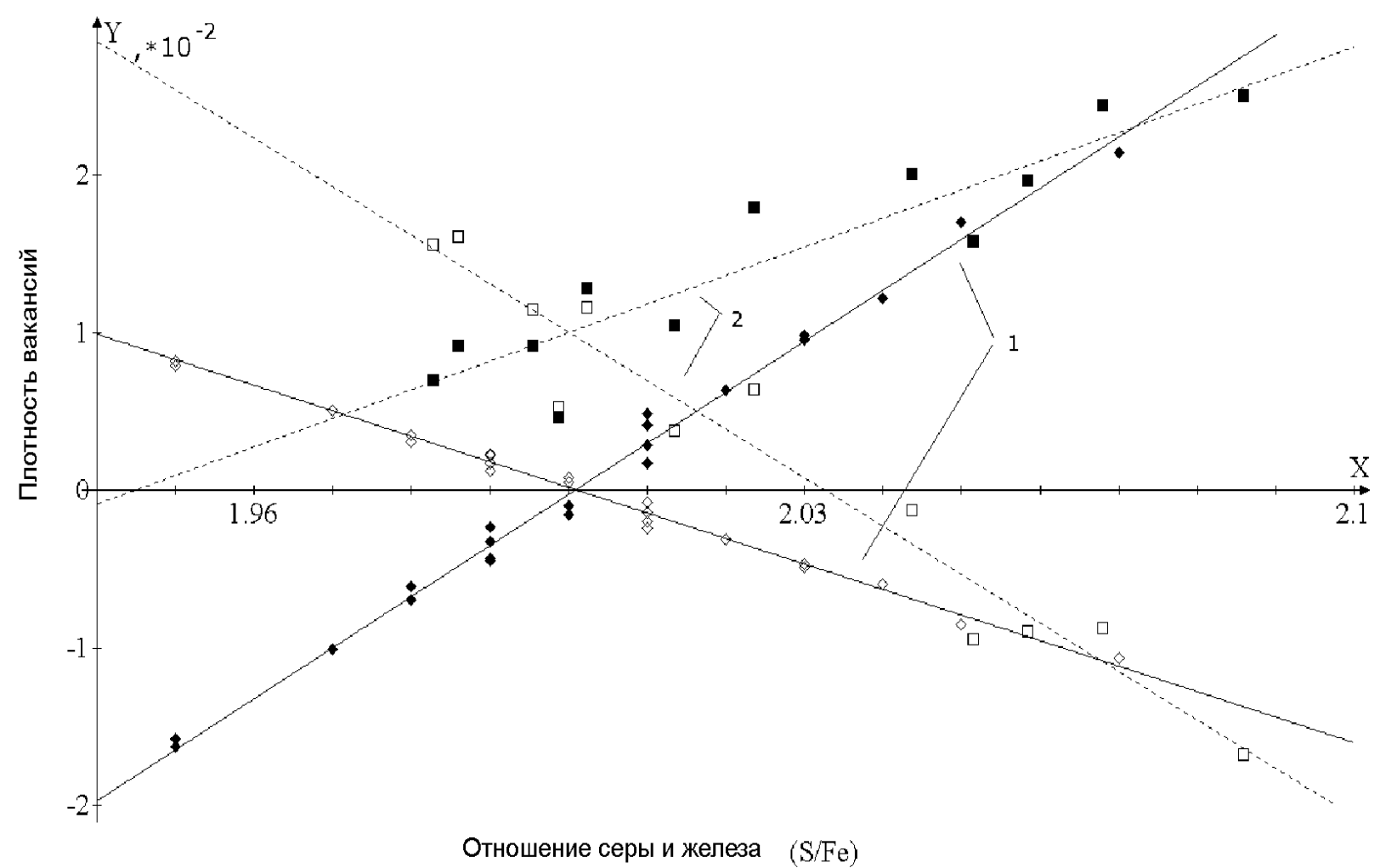

Рисунок 2. Зависимость пирита от глубины его залегания. Кривая 1 - вакансий глубина пирита 50 - 100 м; кривая 2 - вакансии глубина пирита 272 - 284,5 м

Отклонения природного пирита от стехиометрической структуры могут быть заданы формулой $\left(\mathrm{Fe}^{+2}\right)_{\chi}\left(\left(\mathrm{S}_{2}\right)^{-2}\right)_{\tau}$, . «Гантель» из двух атомов серы проще представить одной формульной единицей; здесь плотность анионных вакансий такая же, как плотность вакантных позиций серных «гантелей». Отношение $\mathrm{S} / \mathrm{Fe}$ определяется соотношением $2 \tau / \chi$, поскольку любая «гантельная позиция» занята двумя атомами серы, а плотность катионных вакантных позиций представлена уравнением $(1-\chi)=\mathrm{n}_{1}$, а анионные вакантные позиции представлены уравнением $(1-\tau)=\mathrm{n}_{2}$. 


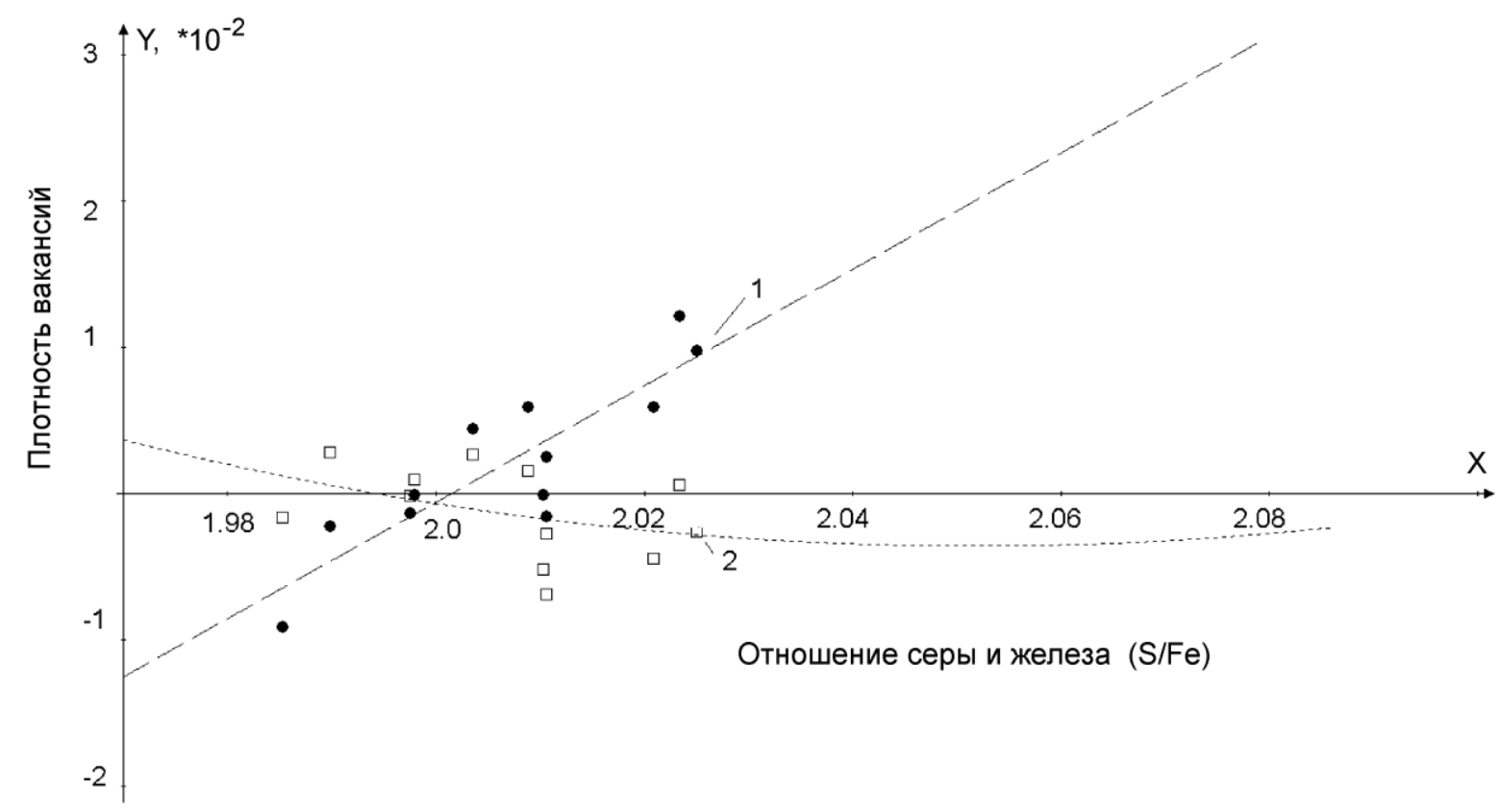

Рисунок 3. Зависимость пирита от глубины его залегания. Кривая 1 - катионных вакансий; кривая 2 - анионные вакансии (глубина залегания пирита 535.6 - 567 м.)

Положительное значение плотности анионных (катионных) вакансий означает их превышение относительно стехиометрического состава. Таким образом, параметры $\chi$ и $\tau$ линейно независимы, поскольку дефицит как серы, так и железа в структуре может возникать одновременно. В этом случае кристаллическая структура находится в метастабильном состоянии, в котором структура может оставаться в течение длительного времени. Через определенное время (время релаксации) происходят процессы рекомбинации вакансий железа и серы, и останется только один тип вакансии (либо сера, либо железо), в зависимости от того, какие вакансии преобладают в начале этой рекомбинации. Если и $\chi$ и $\tau$ равны 1 (стехиометрическая структура $\mathrm{FeS}_{2}$ ), это означает, согласно расчетам, что содержание железа в образце составляет $46.547 \%$ (весовых процентов), а содержание серы $53.453 \%$. Анализ графиков на рис. 2 и рис.3 показывает, что анионные и катионные вакансии чувствительны к глубине пирита и, следовательно, к внешнему давлению. Несмотря на различие в поведении катионных и анионных вакансий, внешнее давление как бы сжимает кривые, существенно сужая область их существования по оси абсцисс $(\mathrm{S} / \mathrm{Fe})$. Причем величина сжатия этих кривых напрямую зависит от внешнего давления, то есть от глубины пирита.

Понятно, что для искажения кристаллической структуры, содержащей вакансии, требуется меньше энергии. Кроме того, энергия, необходимая для такой деформации, зависит от размера вакансий: искажение кристаллической структуры с большими вакансиями требует меньше энергии. Поэтому кривые анионных вакансий стягиваются сильнее, чем кривые катионных вакансий.

Интересно отметить, что точечные дефекты в пирите в подавляющем большинстве представлены ионами кобальта и никеля, то есть элементами, расположенными рядом с железом в таблице Менделеева. Эти элементы отличаются от железа наличием в ядре одного или двух протонов. Можно предположить, что они возникли в результате процессов бетараспада в результате радиоактивности Земли, то есть в результате холодного ядерного синтеза в результате земной радиоактивности, а не существовали изначально.

Выводы. Установлена зависимость катионных и анионных вакансий от отношения $\mathrm{Fe} / \mathrm{S}$ в образцах. Показана зависимость кривых поведения катионных и анионных вакансий от глубины залегания пирита. На малых глубинах ( $50 \mathrm{M})$ зависимость плотности вакансий от химического состава пирита имеет линейный вид, причем проходит через начало координат. 
На глубинах залегания 250м эта зависимость сдвигается по оси Y, однако остается линейной. На достаточно большой глубине залегания пирита ( $550 \mathrm{M})$ линейность нарушается, а сама кривая смещается по оси Y опять вниз. Проведен анализ концентрации точечных дефектов различной природы в структуре пирита, добываемого на разной глубине. Рассчитана плотность вакансий для кубической структуры пирита, залегающего на разной глубине.

$$
* * *
$$

1. Gait R. I., Dumka D. Morphology of pyrite from the Nanisivik mine, Baffin Island, Northwest Territories. // The Canadian Mineralogist. - 1986. - V. 24, P. 685-688.

2. Дир У.А. Хауи Р. А., Зусман Дж. Породообразующие минералы. М. : Мир. 1966. Т.5. 306 с.

3. Онуфриенок В.В. Фазовые соотношения сульфидов железа в метастабильном состоянии// Физика твердого тела. 1991. Т.33. № 7. С. 2213-2215.

4. Кузьмин Е.В., Онуфриенок В.В. Намагниченность нестехиометрических соединений типа пирротин с различной концентрацией вакансий в структуре//Физика твердого тела.1983. Т.25. № 8. С.2321-2326.

5. Онуфриенок В.В. Арсенопирит золотосодержащих руд: состав, позиции примесных атомов, распределение золота// Международный журнал прикладных и фундаментальных исследований. 2013. № 3. С. 43-48

6. Arnold R.G. Equilibrium relation between pyrrhotite and pyrite from 325 to $743^{\circ} \mathrm{C} / /$ Econ.Geol. 1962. V.57. P.7290 .

7. Kullerud G.,Yoder H.S. Pyrite stability relutions in the Fe-S system// Econ.Geol. 1959. V. 54. P. 533-572.

8. Lynch G. Metamorphism of arsenopyrite - pyrite - sphalerite - pyrrhotite lenses. Western Cape Breton Island. Nova scoti // The Canadian Mineralogist - 1995. V. 33. P. 105-114

9. Fleet M.E. Structural aspects of the marcasite-pyrite transformation// The Canadian Mineralogist. 1970. V. 10. P. 225-231.

10. Selivanov E.N., Gulyaeva R.I., and Vershinin A.Д. Thermal Expansion and Phase Transformations of Natural Pyrrhotite// Russian Journal of Inorganic Materialy. 2008. V.44. P. 506-511.

11. Pearson WB The crystal chemistry and physics of metal and alloys. Wiley, New York, 1972. $826 \mathrm{p}$

12. Rickard D., Luther G. Chemistry of Iron Sulfides// Chem. Rev. 2007. V.107. P. 514-565.

13. Vaughan DJ, Craig JR Mineral chemistry of metal sulfides //Cambridge University Press, Cambridge. 1978. $493 \mathrm{p}$

14. Ward J.C. The structure and properties of some iron sulphides// Rev. Pure Appl. Chem. 1970 . V. 20 . P.175-206.

\section{Юров В.М. ${ }^{1}$, Портнов В.С. ${ }^{2}$ \\ Анизотропия толщин поверхностного слоя и энергии связи поверхности щелочных элементов \\ ${ }^{1}$ Карагандинский университет имени Е.А. Букетова \\ ${ }^{2}$ Карагандинский технический университет \\ (Казахстан, Караганда)}

doi: 10.18411/trnio-11-2021-78

\section{Аннотация}

В настоящей статье изучена эмпирическая модель определения толщины поверхностного слоя и анизотропии поверхностной энергии щелочных металлов. Проведено сравнение нашей модели, а именно, расчета анизотропии поверхностной энергии щелочных металлов с моделями, связанными с координационным плавлением кристаллов (одна модель), методом функций Грина (вторая модель) и методом теории функционала плотности (третья модель). Все три модели (вмести с нашей) дают примерно одинаковые результаты, но наша модель определяет анизотропию толщин поверхностного слоя, численное значение которой указывает на наноструктуру щелочных металлов, которое можно определять экспериментально.

Ключевые слова: толщина поверхностного слоя, поверхностная энергия, щелочной металл, анизотропия.

\section{Abstract}

In this article, an empirical model for determining the thickness of the surface layer and the anisotropy of the surface energy of alkali metals is studied. Our model is compared, namely, the calculation of the surface energy anisotropy of alkali metals with models related to the coordination melting of crystals (one model), the Green's function method (the second model) and the method of 